\title{
An unusual intranuclear structure (? viral nucleocapsid) in the brain in subacute sclerosing panencephalitis
}

\author{
A. D. DAYAN ${ }^{1}$, SWATI MAJUMDAR, W. HUGHES, \\ AND K. W. G. HEATHFIELD \\ From the Department of Neuropathology, The National Hospitals, London, \\ and Oldchurch Hospital, Romford
}

SYNOPSIS A brain biopsy was examined from a 7 year old boy with subacute sclerosing panencephalitis. Intranuclear deposits of measles antigens were demonstrated in parenchymal cells by immunofluorescence. Electron microscopy showed viral nucleocapsids in nucleoliform inclusions and unusual rod-like intranuclear structures which resemble structures previously described only in tissue cultures infected with measles virus.

Since the first electron micrographs of Bouteille et al. (1965) a considerable amount of evidence has been obtained that subacute sclerosing panencephalitis represents a temperate infection of the brain by a measles-like virus (see, for example, Sever and Zeman, 1968; ter Meulen et al., 1972). Almost all the ultrastructural studies so far have shown tubular forms of the viral nucleocapsid, and the only variations have depended on changes in the orientation of these long cylindrical objects in the plane of the section (Herndon and Rubinstein, 1968; Oyanagi et al., 1971).

We wish to describe a case in whose brain immunofluorescence and electron microscopy showed conventional forms of virus, as well as a bizarre intranuclear structure that may not have been illustrated previously in vivo.

\section{CASE REPORT}

A boy born in August 1964, was well until February 1971, when he became jaundiced and was diagnosed clinically as suffering from infective hepatitis. He made a good recovery from this illness and returned to school in April. Shortly afterwards his mother noticed that his right hand shook, he became unable 1 Present address: Wellcome Research Laboratories, Langley Court,
Beckenham, Kent BR3 3BS.

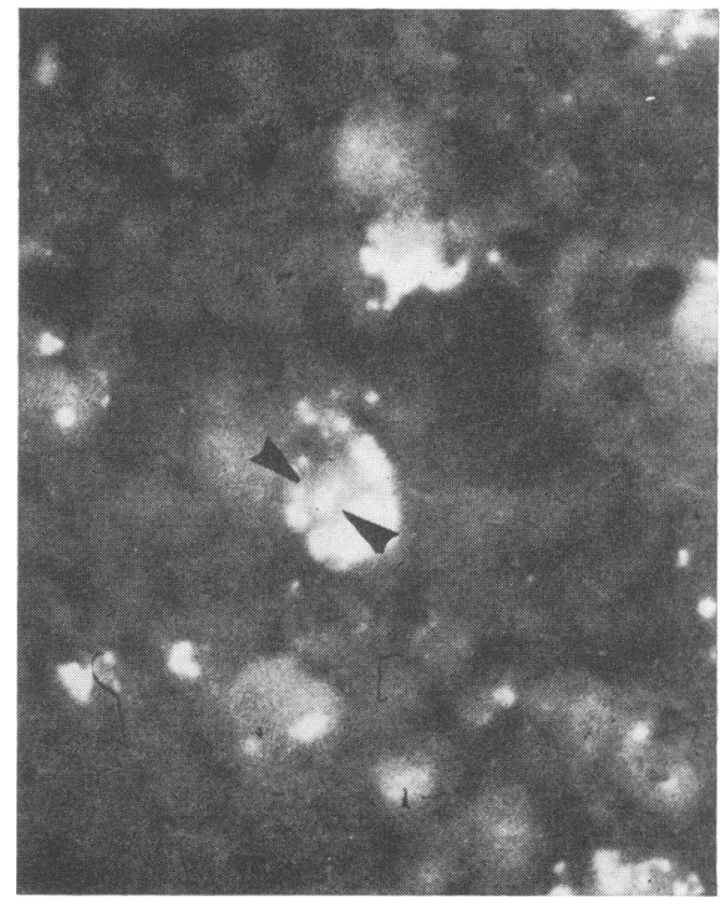

FIG. 1. Immunofluorescence of measles virus-like antigen (arrows) in nucleus of neurone. The other fluorescent granules in the cell were orange-yellow lipofuscin granules. Cryostat section, $\times 400$. 


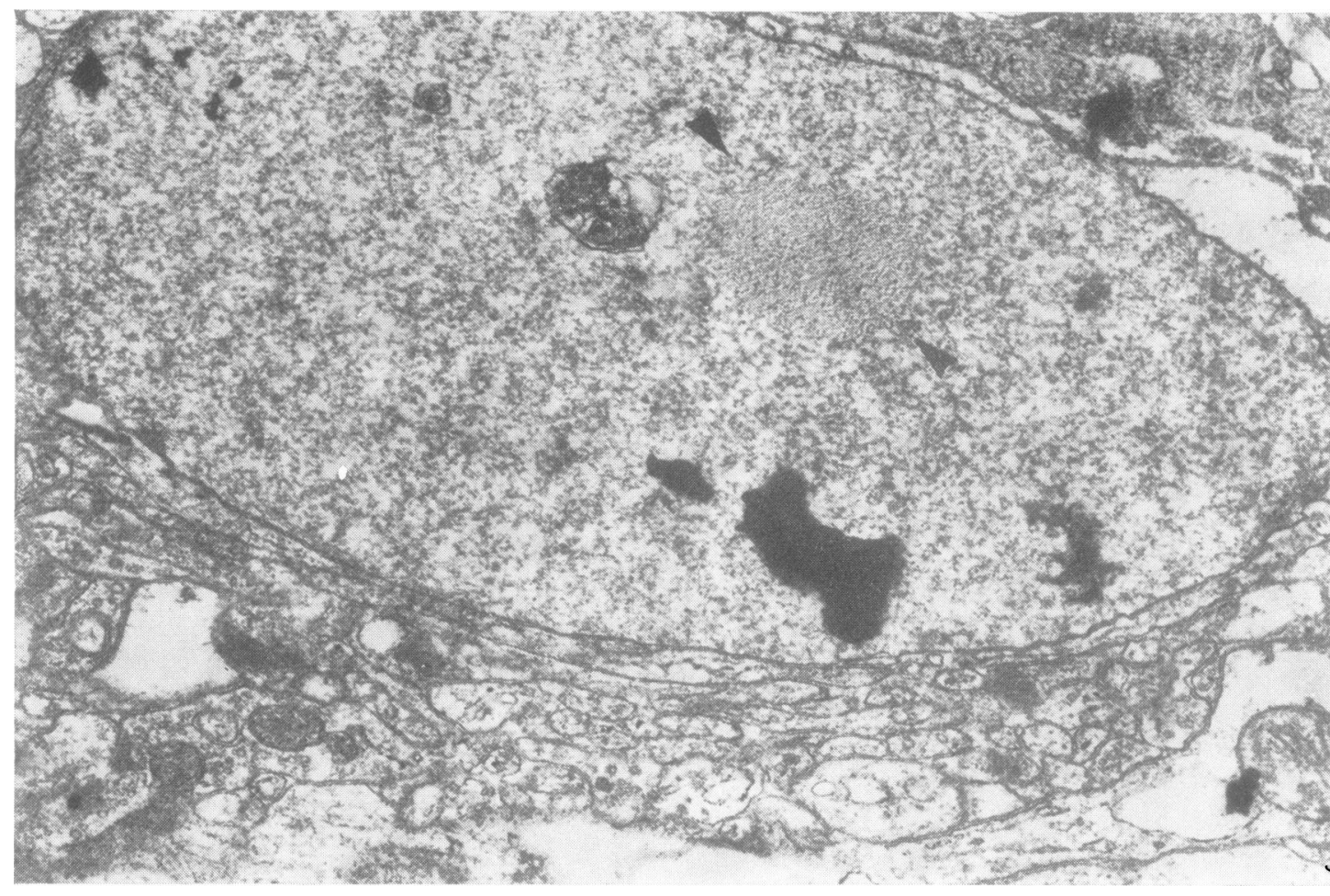

FIG. 2. Rounded intranuclear nucleoliform inclusion of viral tubules (arrows). $\times 8,000$.

to write properly, and his speech became impaired as he was unable to put words together and used baby talk instead. By June these disorders had progressed, his balance also became impaired, and he fell on several occasions. When walking he tended to veer to the right. He became forgetful and no longer seemed to understand commands. His school performance deteriorated greatly. His birth and development previously had been normal. He was the second of four children. He had had a mild attack of measles at the age of 6 months. On admission in July 1971, he was conscious and cooperative. He could no longer read or write; he was able to recognize simple pictures, although unable to describe them. He showed a fine tremor of both outstretched hands and repetitive jerking of the right arm and sometimes of the left. There was a generalized plastic rigidity of the right upper limb. He had a reeling gait and was unable to hop on the right leg. No other abnormal signs were found in the central nervous system. Standard haematological and biochemical tests on blood were normal apart from slightly raised serum transaminases, which returned to normal over the next few months. Re- peated electroencephalograms (EEG) showed a similar abnormality against a background of rhythmic theta activity: every 8 to 15 seconds there were repetitive, high voltage paroxysmal complexes consisting of slow waves intermingled with small sharp waves.

Lumbar cerebrospinal fluid (CSF) contained protein $20 \mathrm{mg} / 100 \mathrm{ml}$., and 1 lymphocyte/cu. mm.

A serum Paul-Bunnell test was negative; hepatitisassociated antigen was not found, nor was there any antibody against it.

Measles antibody titres (reciprocal values) in August 1971 were serum-CFT 2560: HI 16; CSFCFT 32: HI less than 4.

The clinical diagnosis of subacute sclerosing panencephalitis was confirmed by these serological findings and the results of a cortical biopsy (see below).

The patient was still alive after 18 months. The N myoclonus ceased after a few months and for the last nine months he has been stuporose and in a state of decerebrate rigidity. A trial of amantadine $(600 \mathrm{mg}$ 


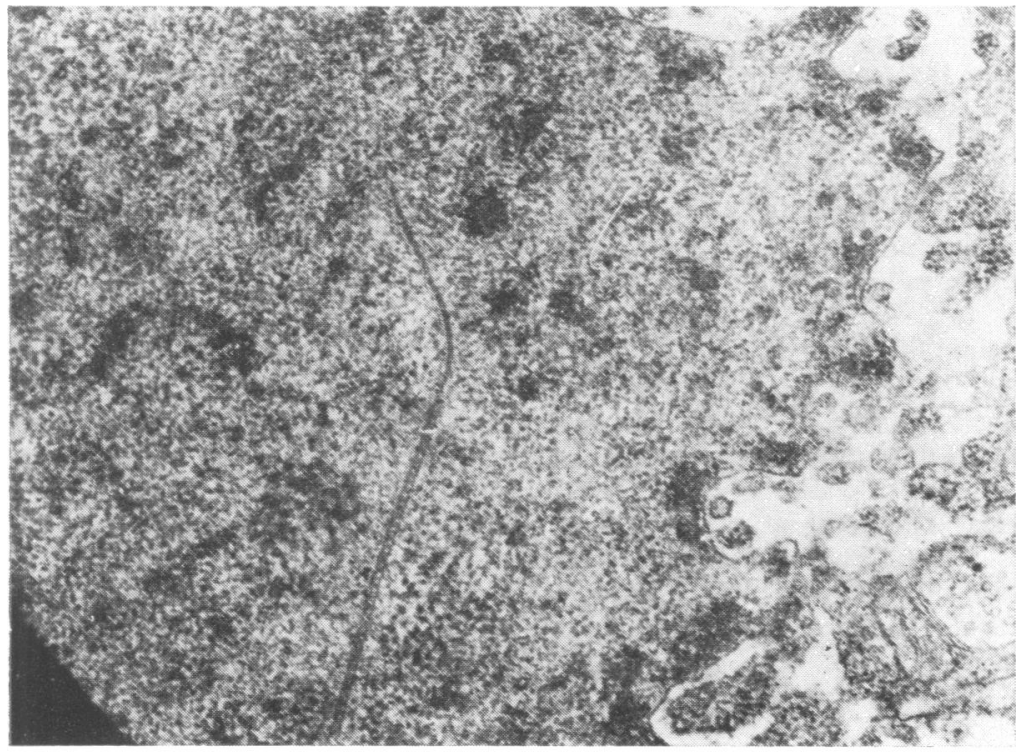

(a)

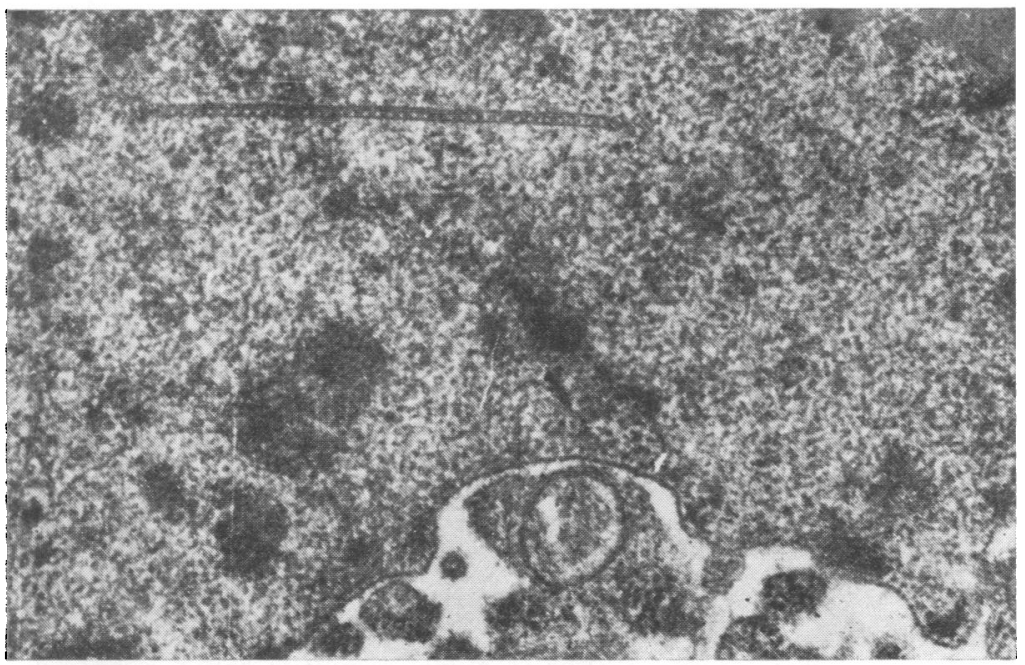

(b)

daily for several weeks) had no apparent effect on the illness.

PATHOLOGICAL STUDIES 1. Light microscopy of the brain biopsy showed a moderately severe subacute encephalitis with increased numbers of rod cells in the cortex, mild perivascular cuffing by inflammatory cells and sparse scattered nodules of neuronophagia. phages.
FIG. 3. (a) and (b) two views of the rod-like intranuclear structures which consisted of repeating subunits and a tail at one end. $\times 11,500$.

In the white matter there was slight gliosis and small numbers of lipid-containing perivascular macro-

No inclusion bodies were seen.

2. Immunofluorescent studies of cryostat sections of the brain were done by the indirect technique using specific, high titre guinea-pig and human measles 
antisera and the appropriate anti-IgG fluoresceinconjugated antiserum.

A small number of neurones (about $1 \%$ ), scattered throughout the cortex, contained solitary intranuclear inclusions of measles-like antigens (Fig. 1). They were round in shape and, although about the same size, were quite distinct from the nucleoli. Specific cytoplasmic fluorescence was not found, although there were occasional golden yellow autofluorescent lipofuscin granules.

Perivascular cells were seen to contain IgG or IgM.

3. Biochemical analysis of the brain (Professor A. N. Davison) revealed slight overall loss of myelin lipids from the white matter and small amounts of cholesterol esters there and in the cortex. The cerebral cortex also showed a slight overall loss of gangliosides, but no qualitative abnormality was demonstrated in the proportions of the various mono- and di-sialo gangliosides normally present.
4. Electron microscopy A portion of the biopsy was fixed in glutaraldehyde, post-fixed in osmic acid, and ultra-thin sections cut after embedding in Araldite. The sections were examined after staining with lead citrate and uranyl acetate.

In the cortex abnormally large numbers of astrocyte processes were seen and darker cells, presumed to be macrophages, which contained prominent dense bodies, reactive lysosomes, and vacuoles filled with lipid debris.

Inclusions were found in the nuclei of occasional parenchymal cells, some of which were considered to be neurones because of their size and the considerable amounts of rough endoplasmic reticulum and occasional microtubules present in their cytoplasm. के The majority of the inclusions consisted of rounded $\overrightarrow{0}$ foci occupying $10-15 \%$ of a nucleus.

At high magnification they consisted of tubules, approximately $18 \mathrm{~nm}$ in diameter, with a regularly repeating substructure. When seen end-on, this type

FIG. 4. A higher power view of part of Fig. 3a showing the subunits of the body and the probable helical twisting of the tail (arrows). $\times 25,000$.

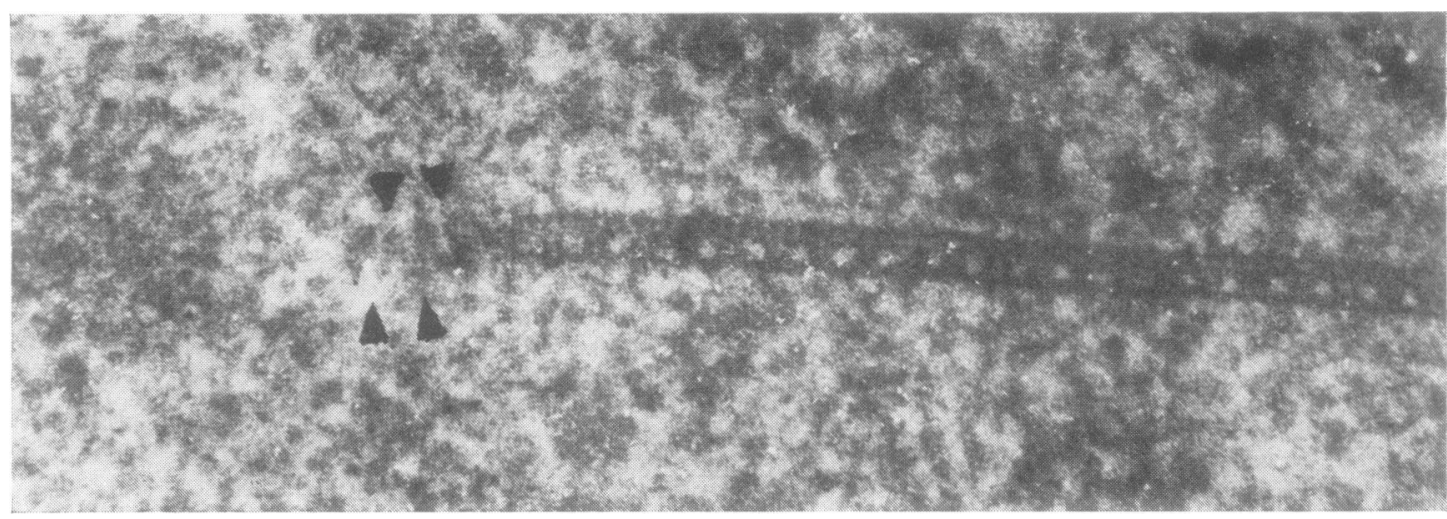

FIG. 5. An enlarged view of part of Fig. $3 b$ showing the tail emerging from the body. $\times 30,000$. 
of inclusion formed a rounded (1-2 $\mathrm{nm}$ diameter), sharply delineated but not membrane-bounded area of greater electron density than the adjacent chromatin (Fig. 2). They were entirely separate from the nucleolus.

The second type of intranuclear structure was less common and it was seen with only about one-sixth the frequency of the more typical structures described above. It consisted of solitary linear bodies (Fig. 3). apparently made up of regularly repeating rectangular sub-units joined end to end (Fig. 4), and enclosing a rod-like core which might lie at the centre or slightly to one side of it. There was a suggestion that the nuclear chromatin granules were aligned along the sides of these structures. Occasionally, at the end of the linear forms, the central core was seen emerging nude from the outer coat (Fig. 5), as a wavy band with a fine regular structure of repeated sub-units. The external diameter of the rods was about 18$20 \mathrm{~nm}$, the length of its large repeating sub-units about $16 \mathrm{~nm}$, and the diameter of the core approximately $8-10 \mathrm{~nm}$.

The linear forms were not found in the same nuclei as the other type of inclusion and neither type was seen in cytoplasm.

\section{DISCUSSION}

The clinical history and examination, serological findings and the results of immunofluorescent examination of the brain biopsy all confirm the diagnosis of subacute sclerosing panencephalitis (SSPE). The transient attack of jaundice five months before the onset of clinical symptoms and signs of SSPE may be of interest in view of Simpson's (1961) account of patients who also had attacks of jaundice preceding SSPE by intervals of a few weeks to several years. Whether this association has any pathogenetic or aetiological significance is unknown, but many mechanisms could be invoked, including liver and brain infection by the same virus, impaired immunity, etc.

The intranuclear bodies, shown by electron microscopy to consist of arrays of tubules (Fig. 2 ), correspond perhaps to the larger 'nucleoliform ' inclusion in SSPE as described by Herndon and Rubinstein (1968). They probably represent an end-on view of the pathogenic viral nucleocapsids which are more often illustrated in the longitudinal plane as tubular structures. These 'classical' inclusions of SSPE corresponded to the intranuclear accumulations of measles-like virus antigens shown by immunofluorescence.

The other structure has not previously been described, either in SSPE or in experimental infections of animals. Its general size, form, and shape, and the presence of a core with repeating units suggest that it could well be another form of viral structure. Allowing for the differences between negatively stained preparations and thin sections, its size and form resemble the partly disrupted measles virus particles obtained from infected cell cultures by Almeida and Howatson (1963); their Fig. 3 shows a typical inner helical ribonucleoprotein core surrounded by an outer, possibly helical, covering which is reminiscent of the structures found in the present case. The alternative is that the intranuclear inclusion is a coincidental finding unrelated to the infection. Against this is the fact that its size and repeating substructure and the appearance of the core do not match any structures previously described, notably the intranuclear filaments analysed in detail by Seïte et al. (1971), and recentlyillustrated by Field and Narang (1972).

Too little is known about the range of ultrastructural appearances of viral replication for any functional interpretation to be based on the occurrence of this particular form in a case of SSPE; certainly from the published evidence so far it must be an extremely rare event.

We are grateful to Professor A. N. Davison for the biochemical analysis, to Dr. J. D. Almeida for her advice and to Mr. J. A. Mills for his assistance.

\section{REFERENCES}

Almeida, J. D., and Howatson, A. F. (1963). A negative staining method for cell-associated virus. Journal of Cell Biology, 16, 616-620.

Bouteille, M., Fontaine, C., Vedrenne, C., and Delarue, J. (1965). Sur un cas d'encéphalite subaiguë à inclusions. Étude anatomo-clinique et ultrastructurale. Revue Neurologique, 113, 454-458.

Field, E. J., and Narang, H. K. (1972). An electron-microscopic study of scrapie in the rat: further observations on 'inclusion bodies' and virus-like particles. Journal of the Neurological Sciences, 17, 347-364.

Herndon, R. M., and Rubinstein, L. J. (1968). Light and electron microscopy observations on the development of viral particles in the inclusions of Dawson's encephalitis (subacute sclerosing panencephalitis). Neurology (Minneap.), 18, no. 1, part 2, pp. 8-20.

Meulen, V. ter, Katz, M., and Müller, D. (1972). Subacute 
sclerosing panencephalitis: a review. Current Topics in Microbiology and Immunology, 57, 1-38.

Oyanagi, S., Meulen, V. ter, Katz, M., and Koprowski, H. (1971). Comparison of subacute sclerosing panencephalitis and measles viruses: an electron microscope study. Journal of Virology, 7, 176-187.

Seïte, R., Escaig, J., and Couineau, S. (1971). Microfilaments et microtubules nucléaires et organisation ultrastructurale des battonnets intranucléaires des neurones sympathiques. Journal of Ultrastructure Research, 37, 449-478.

Sever, J. L., and Zeman, W. (1968). Conference on measles virus and subacute sclerosing panencephalitis. Neurology (Minneap.), 18, no. 1, part 2.

Simpson, J. A. (1961). Subacute inclusion-body encephalitis: a possible association with infective hepatitis. Lancet, 2, 685-687. 